\title{
DISPENSING ERRORS OBSERVED BY COMMUNITY PHARMACY DISPENSERS IN IBB - YEMEN
}

\author{
YASER MOHAMMED AL-WORAFI ${ }^{1,2 *}$
}

${ }^{1}$ Department of Clinical Pharmacy, College of Pharmacy, University of Science and Technology, Yemen. ${ }^{2}$ Department of Clinical Pharmacy, College of Pharmacy, Ajman University, UAE. Email: yworafi@yahoo.com

Received: 10 July 2018, Revised and Accepted: 08 October 2018

ABSTRACT

Objective: The objective of this study was to determine the dispensing errors, its types, and causes in community pharmacies in Ibb, Yemen.

Methods: A prospective study was conducted among community pharmacies in the Ibb, Yemen, over 4 months' period. Dispensing errors that were detected during the dispensing process were recorded by the pharmacy dispensers using a data collection form. Detecting and reporting of dispensing errors, types, and causes of dispensing errors were explained to the participated pharmacists before starting the study. The data were analyzed using the Statistical Package for the Social Sciences ${ }^{\circledR}$ (IBM SPSS) version 21 for Windows.

Results: A total of $35(0.80 \%)$ dispensing errors were reported in this study. Wrong dosage form was the most common dispensing error type reported in this study followed by wrong quantity, wrong strength, and wrong drug. Factors most commonly reported as contributing to dispensing errors in this study were prescriptions poor handwriting, similar medications packaging, more than one patient at the same time, and similar drug names.

Conclusion: This study explored the type and causes of dispensing errors at five community pharmacies in the Ibb city, Yemen. Dispensing errors can be prevented by educational interventions about dispensing error's and its potential causes. Effective collaboration and communication between community pharmacy dispensers and prescribers are an important key to minimize and prevent dispensing errors.

Keywords: Dispensing errors, Community pharmacy, Yemen.

(C) 2018 The Authors. Published by Innovare Academic Sciences Pvt Ltd. This is an open access article under the CC BY license (http://creativecommons. org/licenses/by/4. 0/) DOI: http://dx.doi.org/10.22159/ajpcr.2018.v11i11.28382

\section{INTRODUCTION}

Dispensing medications are the traditional work of pharmacist and other pharmacy dispensers worldwide, and any errors during dispensing process will affect the quality use of medications and may lead to unsafety of use it $[1,2]$. Dispensing errors affect the outcomes of treating patients and potential for increased morbidity, mortality, length of hospitalization, and cost of illness [1,2]. Dispensing errors are an important type of medication errors and defined as "a discrepancy between the prescriber's interpretable written order and the filled prescription including written modifications made by the pharmacist pursuant to contact with the prescriber or in compliance with pharmacy policy," [3] or "errors that occur when distributing or selling prescription to patient's or patient's agents," [4] or "discrepancy between the prescriber's written order and the filled prescription," [5] or "error caught by a pharmacist observer after verification by the pharmacist" [6]. The previous studies worldwide reported the following types of dispensing errors: (1) Wrong drug dispensed, (2) wrong strength dispensed, (3) wrong form dispensed, (4) wrong quantity dispensed, (5) failure to supply drug, (6) labeling error, (7) wrong drug name on label, (8) wrong strength on label, (9) wrong directions and warnings on label, (10) wrong quantity on label, (11) wrong patient name on label, and (12) completely wrong label [3,4,7-16].

There are many causes of dispensing errors and the previous studies worldwide reported the following types of dispensing errors: (1) Similar drug names, (2) similar packaging, (3) staffing levels, (4) prescription writing errors, (5) design of dispensary, (6) staff inexperience, (7) failure to check, (8) lack of procedures, (9) job dissatisfaction, (10) poor communication, (11) computer software, (12) noise, (13) proximity of drugs on shelves, (13) no breaks, (14) failure to follow standard operating procedures, (15) hunger, (16) fatigue, (17) stress, (18) lack of training, (19) lack of concentration, (20) lighting, (21) lone worker, (22) complex prescription, and (23) lack of knowledge [13-17].
There is a lack of study about dispensing errors in Yemen. Therefore, the aim of this study was to describe the dispensing errors, its types, and causes in selected community pharmacies in the Ibb city, Yemen.

\section{METHODS}

\section{Study design and setting}

A prospective study was carried out in among community pharmacies in Ibb, Yemen, over 4 months from March 1 till the end of June 2016. The inclusion criteria were community pharmacies located within the city of Ibb. A sampling frame of all the eligible pharmacies was prepared and 30 community pharmacies were invited to participate, but only seven community pharmacies were given consent to participate in the study.

\section{Data collection procedure}

Data were collected over 4 months. A standardized data collection form (Table 1) was prepared to facilitate the data collection procedure.

Dispensing error in this context is defined as "errors that occur when distributing or selling prescription to patient's or patient's agents" [4]. Dispensing errors that were detected during or after the dispensing process were recorded by the pharmacy dispensers using a data collection form. Detecting and reporting of dispensing errors, types, and causes of dispensing errors were explained to the participated pharmacy dispensers before starting the study through workshops, educational materials, and training.

\section{Statistical analysis}

The data were descriptively analyzed using the Statistical Package for the Social Sciences ${ }^{\circledR}$ (IBM SPSS) version 21 for Windows. Differences in proportional were tested with Chi-square test or Fisher's exact test. Differences test in the means was test with the Student's t-test. All reported $\mathrm{p}$-values are two-tailed, and the result is significant if $\mathrm{p} \leq 0.05$. 
Table 1: Dispensing error collection form

\begin{tabular}{llllll}
\hline $\begin{array}{l}\text { Prescription } \\
\text { No }\end{array}$ & $\begin{array}{l}\text { Date and time of } \\
\text { dispensing error }\end{array}$ & $\begin{array}{l}\text { Who made, found the } \\
\text { error and how discovered }\end{array}$ & $\begin{array}{l}\text { Type of } \\
\text { error }\end{array}$ & $\begin{array}{l}\text { Cause of } \\
\text { error }\end{array}$ & $\begin{array}{l}\text { Other details } \\
\text { of error }\end{array}$ \\
\hline
\end{tabular}

\section{Ethical approval}

This study was approved from the University of Science and Technology, Yemen. Consent was obtained from the community pharmacy managers and community pharmacy dispensers. No personal information of the community pharmacies, community pharmacy dispensers, and patients were collected.

\section{RESULTS}

One community pharmacist and 12 pharmacy technicians were working in the five community pharmacies. The mean age of the community pharmacy dispensers was $29.29 \pm 3.09$ years.

The characteristics of the study sample are presented in Table 2 .

\section{INCIDENCE OF DISPENSING ERRORS}

A total of 4325 prescriptions were checked for the dispensing errors during the time of this study. A total of $35(0.80 \%)$ dispensing errors were detected and reported in this study.

\section{WHO MADE THE ERRORS}

The findings of this study show that all pharmacy dispensers except one pharmacy technicians reported that they made at least one dispensing error. The numbers of errors mean were $2.77 \pm 1.16$. The range of errors was between 0 and 5 . There were no significant differences between the pharmacist and pharmacist technicians in terms of who made the errors $(p=1.000)$. There were no significant differences between the pharmacist and pharmacist technicians in terms of the number of errors ( $p=0.847)$. Table 3 shows the number of dispensing errors among participants.

\section{Type of dispensing errors}

Types of dispensing errors are presented in Table 4.

\section{Causes of dispensing errors}

Causes of dispensing errors are presented in Table 5.

\section{DISCUSSION}

The majority of pharmacy dispensers in this study were pharmacy technicians (12/13), and this is consistent with the previous report that the ratio of pharmacists working in community pharmacies in Yemen to the number of pharmacy technicians is low [18-24]. The results of this study showed that all the pharmacy dispensers in the five community pharmacies were male, and this is similar to the previous studies and could be due to that the percentage of pharmacy male students is about $70 \%$ of the total students and culture issues in Yemen [18-21].

A total of $35(0.80 \%)$ dispensing errors were detected and reported in this study. The incidence rate of dispensing errors in this study difference from the reported in other studies worldwide [3,4,7-16]. The difference could be due to the study setting, dispensing errors definitions, and methods.
Table 2: Sociodemographic characteristics of the community pharmacy dispensers

\begin{tabular}{ll}
\hline Variable & Frequency (\%) \\
\hline Gender & $13(100)$ \\
Male & $0(0)$ \\
Female & $1(7.7)$ \\
Qualifications & $12(92.3)$ \\
Bachelor & \\
Diploma & $1(7.7)$ \\
Job & $12(92.3)$ \\
Pharmacist & \\
Pharmacy technician & $3(23.1)$ \\
Experience years & $6(46.2)$ \\
$<5$ & $4(30.8)$ \\
5-10 & \\
More than 10 & $13(100)$ \\
Graduation country & $0(0)$ \\
Yemen & \\
Others &
\end{tabular}

Table 3: Who made the dispensing errors?

\begin{tabular}{ll}
\hline $\begin{array}{l}\text { Who made the } \\
\text { dispensing errors? }\end{array}$ & $\begin{array}{l}\text { Number of reported } \\
\text { dispensing errors }\end{array}$ \\
\hline Pharmacist 1 & 3 \\
Pharmacy technician 1 & 3 \\
Pharmacy technician 2 & 3 \\
Pharmacy technician 3 & 2 \\
Pharmacy technician 4 & 4 \\
Pharmacy technician 5 & 3 \\
Pharmacy technician 6 & 3 \\
Pharmacy technician 7 & 5 \\
Pharmacy technician 8 & 0 \\
Pharmacy technician 9 & 2 \\
Pharmacy technician 10 & 2 \\
Pharmacy technician 11 & 3 \\
Pharmacy technician 12 & 3 \\
\hline
\end{tabular}

Table 4: Type of dispensing errors $(n=35)$

\begin{tabular}{ll}
\hline Types of errors & $\mathbf{n}(\mathbf{\%})$ \\
\hline Wrong dosage form & $16(45.7)$ \\
Wrong quantity & $13(37.1)$ \\
Wrong strength & $5(14.3)$ \\
Wrong drug & $1(2.9)$ \\
\hline
\end{tabular}

The findings of this study show that all pharmacy dispensers except one pharmacy technicians reported that they made at least one dispensing error. The numbers of errors mean were $2.77 \pm 1.16$. The range of errors was between 0 and 5 . There were no significant differences between the pharmacist and pharmacist technicians in terms of who made the 


\section{Table 5: Causes of dispensing errors}

\begin{tabular}{ll}
\hline Causes of errors & n (\%) \\
\hline Prescriptions poor handwriting & $17(48.6)$ \\
Similar medications packaging & $9(25.7)$ \\
More than one patient at the same time & $5(14.3)$ \\
Similar medications names & $4(11.4)$ \\
\hline
\end{tabular}

errors $(p=1.000)$. There were no significant differences between the pharmacist and pharmacist technicians in terms of the number of errors ( $\mathrm{p}=0.847$ ). Wrong dosage form was the most common dispensing error type (45.7\%), then wrong quantity (37.1\%) and wrong strength $(14.3 \%)$. Finally, the least common dispensing error reported in this study was wrong drug $(2.9 \%)$. The findings of this study show that the contributing factors to the dispensing errors were prescriptions poor handwriting (48.6\%), similar medications packaging (25.7\%), more than one patient at the same time (14.3\%), and similar medications names (11.4\%). The reported types and causes of dispensing errors in this study also reported in the previous studies [3,4,7-16] with differences in the percentage of each type and cause, and this difference could be due to the study setting, dispensing errors definitions, and methods of the previous studies. Handwritten prescription errors were found to be the most contributing factors to the reported dispensing errors in this study and this is similar to the previous two studies in Sana'a Yemen $[22,23]$

Poor quality of prescriptions writing can lead to misinterpretation by pharmacy dispensers and will lead to several drug-related problems. Good quality prescriptions are very important for minimizing errors in the dispensing of medications; physicians should adhere to the guidelines for prescription writing for the quality of the treatment of patients. All prescriptions should contain accurate and appropriate information about the patient and the medication that is being prescribed. All prescriptions should contain prescriber's name, address, telephone number, and signature; patient's name, address, age, and weight; prescription date; and drug name, formulation, strength, dose, frequency of administration, quantity prescribed, why prescribed, and instructions for use [22-24]. Literature reported the following strategies for minimizing dispensing errors: "(1) Ensure correct entry of the prescription, (2) confirm that the prescription is correct and complete, (3) beware of look-alike, sound-alike drugs, (4) be careful with zeros and abbreviations, (5) organize the workplace, (6) reduce distraction when possible, (7) focus on reducing stress and balancing heavy workloads, (8) take the time to store drugs properly, (9) thoroughly check all prescriptions, and (10) always provide thorough patient counseling"[25]. Improving the knowledge of health-care professionals about medication errors as well as its report could lead to minimize the incidence of medication errors [26,27]. The teaching and training of community pharmacy dispensers about dispensing errors as well as collaboration and communication with the prescribers are the keys to minimize and prevent dispensing errors.

\section{CONCLUSION}

Wrong dosage form, wrong quantity, wrong strength, and wrong drug were reported as the most common types of dispensing errors in this study. The reported contributing factors to the dispensing errors were prescriptions poor handwriting, similar medications packaging, more than one patient at the same time, and similar medications names. The limitations of this study were design of study itself as it was selfreported which may lead to underreport of dispensing errors and sample size and location of this study are low as only five pharmacies in one city (Ibb city) accepted to share and participated in this study. Study of the dispensing errors incidence in other cities within Yemen, its types, and causes of dispensing errors are strongly recommended.

Study the impact of different interventions to improve dispensing quality, reducing and preventing dispensing errors are strongly recommended. The teaching and training of health-care professionals about medication errors as well as collaboration and communication are the key to minimize and prevent dispensing errors as well as other medication errors.

\section{AUTHOR'S CONTRIBUTION}

Al-Worafi YM designed the study, developed the data collection form, analyzed the data, and drafting the manuscript.

\section{ACKNOWLEDGMENTS}

The authors would like to thank the Community Pharmacists and Pharmacy Technicians for their participation in this study.

\section{CONFLICTS OF INTEREST}

The author declared that there are no conflicts of interest.

\section{REFERENCES}

1. US Food and Drug Administration. Medication Errors. Available from: http://www.fda.gov/drugs/drugsafety/medicationerrors. [Last accessed on 2015 Dec 12]

2. van den Bemt PM, Egberts AC. Drug related problems: Definitions and classification. Eur J Hosp Pharm Pract 2007;13:62-4.

3. Flynn EA, Barker KN, Carnahan BJ. National observational study of prescription dispensing accuracy and safety in 50 pharmacies. J Am Pharm Assoc (Wash) 2003;43:191-200.

4. Hoxsie DM, Keller AE, Armstrong EP. Analysis of community pharmacy workflow processes in preventing dispensing errors. J Pharm Pract 2006;19:124-30.

5. Flynn EA, Barker KN. Effect of an automated dispensing system on errors in two pharmacies. J Am Pharm Assoc (2003) 2006;46:613-5.

6. Oswald S, Caldwell R. Dispensing error rate after implementation of an automated pharmacy carousel system. Am J Health Syst Pharm 2007;64:1427-31.

7. Chua SS, Wong IC, Edmondson H, Allen C, Chow J, Peacham J, et al. A feasibility study for recording of dispensing errors and near misses' in four UK primary care pharmacies. Drug Saf 2003;26:803-13.

8. Ashcroft DM, Quinlan P, Blenkinsopp A. Prospective study of the incidence, nature and causes of dispensing errors in community pharmacies. Pharmacoepidemiol Drug Saf 2005;14:327-32.

9. Franklin BD, O'Grady K. Dispensing errors in community pharmacy: Frequency, clinical significance and potential impact of authentication at the point of dispensing. Int J Pharm Pract 2007;15:273-81.

10. Allan EL, Barker KN, Malloy MJ, Heller WM. Dispensing errors and counseling in community practice. Am Pharm 1995;NS35:25-33.

11. Flynn EA, Dorris NT, Holman, GT Camahan BJ, Barker KN. Medication dispensing errors in community pharmacies: A nationwide study. Proc Hum Factor Ergon Soc 2002;46:48-51.

12. James KL, Barlow D, McArtney R, Hiom S, Roberts D, Whittlesea C, et al. Incidence, type and causes of dispensing errors: A review of the literature. Int J Pharm Pract 2009;17:9-30.

13. Szeinbach S, Seoane-Vazquez E, Parekh A, Herderick M. Dispensing errors in community pharmacy: Perceived influence of sociotechnical factors. Int J Qual Health Care 2007;19:203-9.

14. Varadarajan R, Barker KN, Flynn EA, Thomas RE. Comparison of two error-detection methods in a mail service pharmacy serving health facilities. J Am Pharm Assoc (2003) 2008;48:371-8

15. Peterson GM, Wu MS, Bergin JK. Pharmacist's attitudes towards dispensing errors: Their causes and prevention. J Clin Pharm Ther 1999;24:57-71.

16. Knudsen P, Herborg H, Mortensen AR, Knudsen M, Hellebek A. Preventing medication errors in community pharmacy: Frequency and seriousness of medication errors. Qual Saf Health Care 2007;16:291-6.

17. Bond CA, Raehl CL. Pharmacists' assessment of dispensing errors: Risk factors, practice sites, professional functions, and satisfaction. Pharmacotherapy 2001;21:614-26.

18. Al-Worafi YM. Pharmacy practice and its challenges in Yemen. Australas Med J 2014;7:17-23.

19. Al-Worafi YM. Appropriateness of metered-dose inhaler use in Yemeni community pharmacies. J Taibah Univ Med Sci 2015;10:353-8.

20. Al-Worafi YM. Pharmacy education in Yemen. Am J Pharm Educ 2013;77:65

21. Al-Worafi YM. The challenges of pharmacy education in Yemen. Am J 
Pharm Educ 2014;78:146.

22. Mohammed Al-Worafi Y, Patel RP, Zaidi ST, Mohammed Alseragi W, Saeed Almutairi M, Saleh Alkhoshaiban A, et al. Completeness and legibility of handwritten prescriptions in Sana'a, Yemen. Med Princ Pract 2018;27:290-2

23. Al-Worafi YM. Prescription writing errors at a tertiary care hospital in Yemen: Prevalence, types, causes and recommendations. Am J Pharm Health Res 2014;2:133-40.

24. Al-Worafi YM, Kassab YW, Alseragi WM, Almutairi MS, Ahmed A, Ming LC, et al. Pharmacovigilance and adverse drug reaction reporting: A perspective of community pharmacists and pharmacy technicians in
Sana'a, Yemen. Ther Clin Risk Manag 2017:13:1175-81.

25. Nair RP, Kappil D, Woods TM. 10 Strategies for Minimizing Dispensing Errors. Pharmacy Times. 2010. Available from: http:/ www.pharmacytimes.com/publications/issue/2010/january2010/ p2pdispensingerrors-0110.

26. Jaykare SC. Medication errors, what healthcare providers thınk? A knowledge, attıtude and practice survey. Asian J Pharm Clin Res 2013;6:57-9.

27. Sinha G, Acharya LD, Thunga G, Mathews T. A study of medication errors in general medicine wards of the South Indian tertiary care hospital. Asian J Pharm Clin Res 2016;9:196-200. 